\title{
EL PACIENTE QUE PADECE UN TRASTORNO PSICÓTICO EN EL TRABAJO: DIAGNÓSTICO Y TRATAMIENTO
}

\author{
JOSÉ CARLOS MINGOTE ADÁN*, PABLO DEL PINO CUADRADO*, \\ ÁLVARO HUIDOBRO**, DOLORES GUTIÉRREZ GARCÍA***, \\ ISABEL DE MIGUEL PECIÑA****, MACARENA GÁLVEZ HERRER*****
}

AgRADECIMIENTOS:

Mercedes Herraiz Cruz por el trabajo de redacción y revisión de estilo en la homogeneización de las aportaciones de los diferentes autores.

(*) Psiquiatra del Plan de Atención Integral al Personal Sanitario Enfermo.

(**) Psiquiatra. Centro de Salud Mental de Villaverde.

(***) Trabajador Social del Plan de Atención Integral al Personal Sanitario Enfermo.

$$
\begin{aligned}
& (* * * *) \text { Enfermera } \\
& (* * * * *) \text { Psicóloga }
\end{aligned}
$$

\section{INTRODUCCIÓN PSICOPATOLÓGICA}

La palabra psicosis se ha utilizado en Psiquiatría con significados muy diferentes. En ocasiones ha servido para agrupar a todos aquellos pacientes que en algún momento de su enfermedad mental sufren una alteración grave en su conexión con la realidad; así se denominaban psicosis orgánicas a las demencias y al delirium, psicosis tóxicas a los trastornos mentales graves inducidos por sustancias y se hablaba de psicosis maníaco-depresiva para describir a los trastornos bipolares. Daba lo mismo que la causa de esa desconexión de la realidad fuera una enfermedad conocida (enfermedad de Alzheimer), una sustancia (cocaína) o alguna alteración pendiente de caracterizar (esquizofrenia). Incluso se ha llegado a llamar psicótico a todo paciente grave, sobre todo cuando se evidenciaba un deterioro de su funcionamiento. Actualmente se prefiere utilizar la expresión episodio psicótico para calificar a un tipo de síntomas (delirios y alucinaciones) que pueden aparecer en diversas enfermedades médicas o psiquiátricas y que implican una distorsión de la realidad, bien en la esfera del pensamiento (delirios), bien en la esfera perceptiva (alucinaciones).

Por delirio entendemos una alteración del contenido del pensamiento que supone la aparición de una idea falsa y vivida con total certeza subjetiva, que no se modifica con la argumentación lógica. En ocasiones esta idea o creencia tiene un tema prácticamente imposible (influencia de seres extraterrestres en mi cuerpo) pero también podemos ver delirios con temas cotidianos (celos, culpa, persecución); en cualquier caso en paciente vive su delirio con la misma certeza de realidad que las ideas normales.

En la "interpretación delirante" el paciente distorsiona el sentido o la intención de sus vivencias adaptándola a un delirio preformado o generando una ideación delirante. En el diagnóstico diferencial del delirio entran las ideas erróneas, las ideas sobrevaloradas y las ideas obsesivas. Una idea errónea surge de la falta de información (la Tierra es redonda) o de una capacidad intelectual limitada; en ocasiones un estado de ánimo alterado conduce a creencias erróneas (cuando estamos ansiosos podemos pensar que los demás se dan cuenta); este tipo de ideas se corrigen con la información y no son irreversibles. Las ideas sobrevaloradas se sostienen con firmeza e influyen en nuestro comportamiento (ideas políticas o religiosas) pero se reconoce su carácter subjetivo; no son vividas como una convicción si no como una opción. Las ideas obsesivas aparecen en la mente del enfermo con carácter involuntario y repetitivo; suelen ser absurdas o al menos improbables (ideas de contaminación); el paciente reconoce que parten de su propia mente y lucha contra ellas para eliminarlas de su pensamiento; pueden conducir modificaciones del comportamiento (compulsiones) con la finalidad de disminuir la ansiedad.

No existe una correlación suficiente entre el contenido de un delirio y la enfermedad que lo produce. El delirio más frecuente es el de persecución o perjuicio; puede verse en la práctica totalidad de enfermedades psiquiátricas graves, si bien toma especial 
importancia en la esquizofrenia (poco estructurado) $\mathrm{y}$ en la paranoia (en donde se estructura de una forma muy lógica). Los pacientes con deterioro cognitivo grave (demencias, delirium) también tienden a presentar este delirio, aunque su estructura interna suele ser muy pobre. En la depresión se describen como típicos los delirios de culpa, ruina y enfermedad, mientras que en la manía el delirio típico es el de grandeza. Los delirios de influencia y control (lectura del pensamiento, control de los movimientos) son típicos de la esquizofrenia, pero se pueden ver en otras enfermedades.

Las alucinaciones son alteraciones de la percepción; en ellas el paciente tiene una percepción en ausencia de estímulo externo que la produzca. Las más frecuentes son las alucinaciones auditivas, pero se pueden ver en todas las modalidades sensoriales. Las alucinaciones visuales sugieren un origen orgánico (delirium, tóxicos) y las olfativas y gustativas se han relacionado con alteraciones en el lóbulo temporal. El enfermo puede variar en su grado de convicción con respecto a las alucinaciones; cuando es capaz de reconocer la imposibilidad del fenómeno aunque lo perciba se habla de alucinosis; son típicas de alteraciones en los sistemas de percepción, bien por enfermedades (p.ej. el vértigo de la enfermedad de Meniere) bien por tóxicos (p.ej. las alucinaciones inducidas por LSD). Aunque las alucinaciones sugieren un trastorno mental grave existe una excepción; en la transición vigilia-sueño se pueden ver alucinaciones (hipnagógicas) de tipo visual o auditivo que no implican necesariamente la existencia de patología.

Las ilusiones sensoriales pueden calificarse erróneamente como alucinaciones, pero en ellas existe un objeto externo que es deformado por diversos factores; el estado de ánimo origina cambios en la percepción de los objetos (cuando estamos asustados vemos personas un donde sólo hay sombras); también el nivel de conciencia, el cansancio, los tóxicos y las condiciones en las que se produce la percepción pueden inducir errores sensoriales (por la noche todos los gatos son pardos).

La aparición de delirios y alucinaciones indica la presencia de una trastorno mental grave pero ambos son síntomas con los que muchos pacientes se sienten incómodos y son reacios a comunicarlos. Es frecuente que un enfermo oculte sus ideas delirantes o sus alucinaciones por lo que necesitaremos conducir la entrevista con cuidado para no provocar su negativa a hablar; puede ser necesaria recoger información de terceras personas que nos describan su comportamiento por si hay signos de que esté influido por síntomas psicóticos.
La duración de un episodio psicótico y el funcionamiento mental previo al episodio, más que la gravedad o intensidad de los síntomas, van a determinar en gran medida su comprensión y filiación diagnóstica-pronóstica.

El Trastorno Psicótico Breve ("Bouffée delirante o "descompensación psicótica" o "psicosis reactiva") es un síndrome psicótico agudo y transitorio que persiste de un día a un mes, con posterior recuperación completa del nivel de funcionamiento psíquico premórbido. Suele sobrevenir en respuesta a un factor o factores de estrés psicosocial relevantes en la vida del paciente. El DSM-IV-TR diferencia los Episodios Psicóticos (E.P.) Breves con notorio estrés, sin estrés determinado y de inicio postparto.

Los E.P. Breves suelen afectar a pacientes con Trastorno de Personalidad (T.P.) especialmente T. P. Límite, T.P. Histriónico, Esquizotípico y Esquizóide, de mayor vulnerabilidad psicológica y/o biológica.

\section{DIAGNÓSTICO DIFERENCIAL}

Una vez confirmada la presencia de estos síntomas conviene realizar una evaluación de sus posibles causas. El primer paso será comprobar el nivel de conciencia y la capacidad de atención y concentración; cuando estas función están alteradas lo más probable es que se trate de un síndrome confusional agudo (delirium), debiendo entonces proceder de una forma sistemática para averiguar su origen. Si el nivel de conciencia y la atención están preservados conviene explorar las funciones intelectuales, pues no es infrecuente diagnosticar una demencia tras un episodio psicótico en el anciano. Descartadas estas dos posibilidades queda una lista muy variada de enfermedades, fármacos y tóxicos que deberán ser descartadas mediante la historia clínica, la exploración física y las pruebas complementarias correspondientes. Tras realizar este estudio se podrá asumir el diagnóstico de un probable trastorno psicótico primario, debiendo derivar al paciente al especialista para que precise el tipo (esquizofrenia, paranoia, trastornos afectivos con síntomas psicóticos).

Aparte de los síndromes psicóticos secundarios a una enfermedad médica o sustancia determinada, la esquizofrenia y el trastorno delirante son los dos principales trastornos mentales graves, caracterizados por el cuadro clínico psicótico, la evolución en el tiempo y el grado de discapacidad asociado.

En la tabla 1 se esquematizan las principales causas de síndromes psicóticos agudos. 
Tabla 1

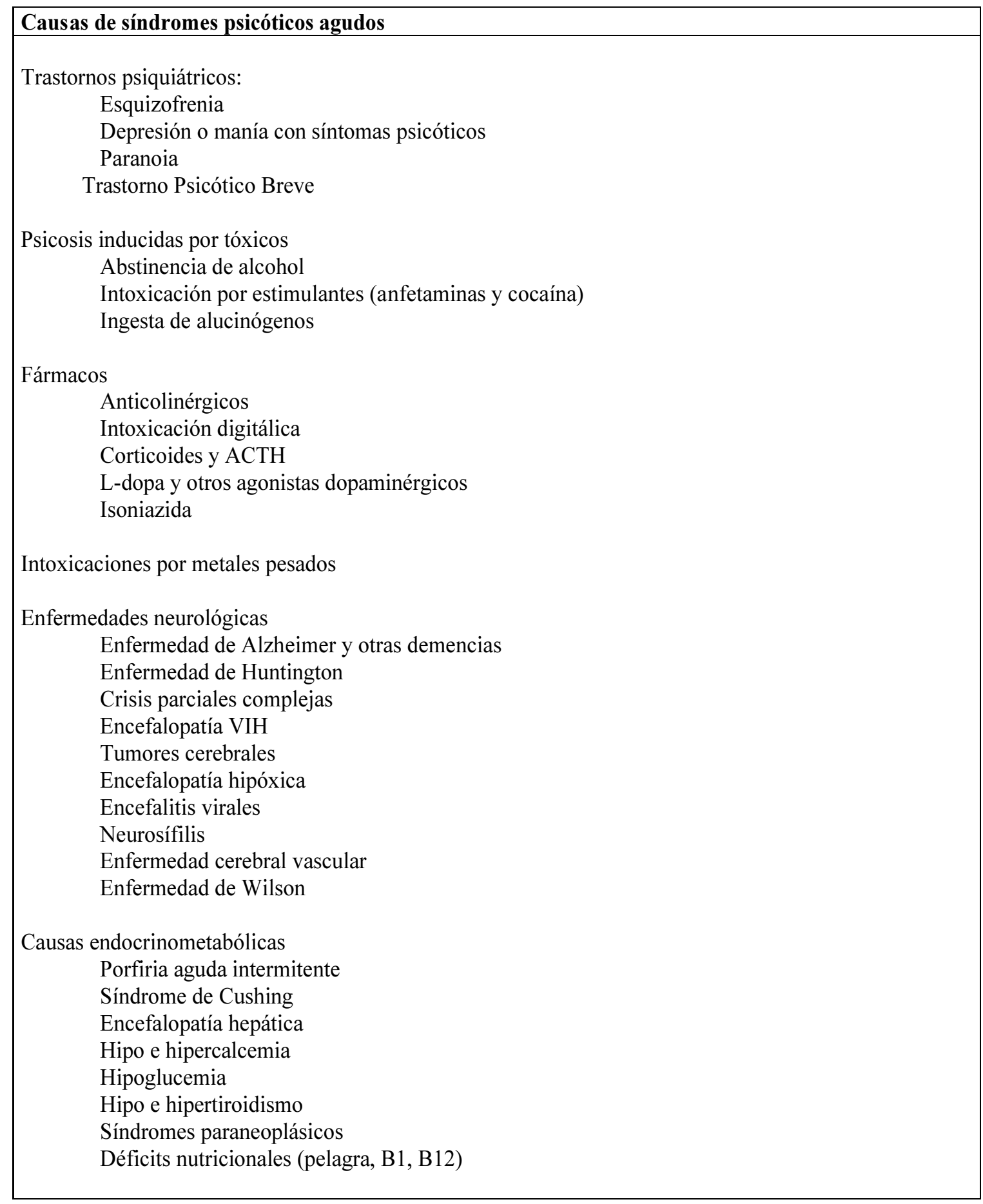

En la práctica clínica suele ser de gran utilidad al plantearnos el diagnóstico diferencial de un episodio psicótico utilizar árboles de decisiones diagnósticas
(Vallejo, 2006). Como ejemplo práctico proponemos el incluído en la tabla 


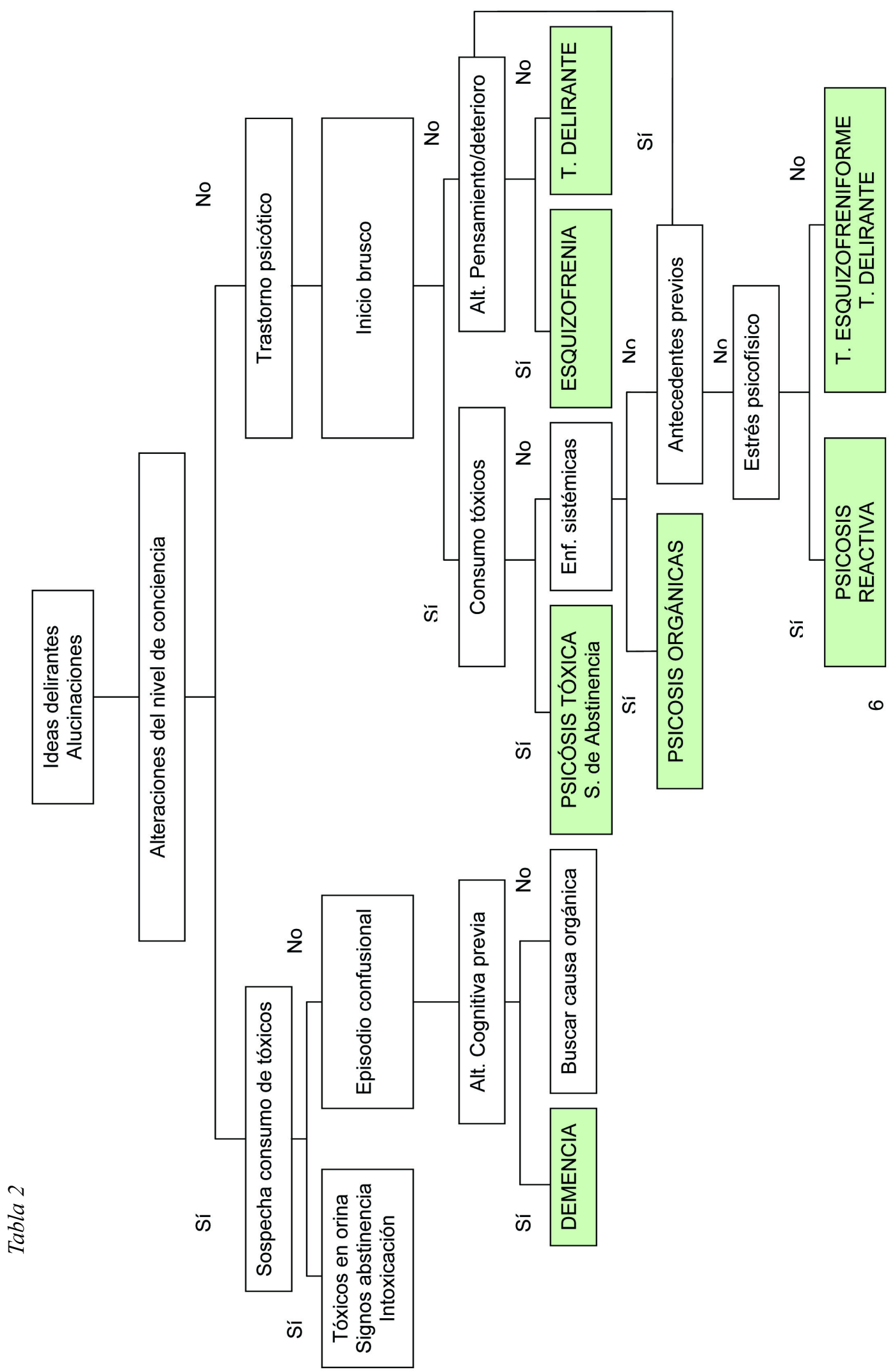


En el diagnóstico diferencial de un E. P., una vez descartadas las causas orgánicas y tóxicas, debemos prestar especial atención al proceso psicopatológico de base, la forma de inicio y la duración del E. P. porque puede ser de mucha utilidad para orientar el diagnóstico y el tratamiento del paciente individual.

El T. Psicótico Breve, habitualmente de comienzo brusco, presenta a diferencia de los T. Psicóticos Crónicos (Esquizofrenia, Paranoia) labilidad emocional, comportamiento extraño, gritos o mutismos y alteración de la memoria reciente.

Los autores europeos centran el patrón sintomático en reacciones paranóides agudas, confusión reactiva, y extrema ansiedad-inquietud o depresión reactiva.

Los delirios polimorfos, perplejidad y vivencias de despersonalización-desrealización con alucinaciones ocasionales sería otro perfil, más propio de las descompensaciones psicóticas en los T. de Personalidad Histriónicos graves.

Si los síntomas psicóticos están presentes durante más de un mes, debemos pensar en la posibilidad de que se trata de trastornos crónicos. Además de la Esquizofrenia y la Paranoia ha de considerarse los Trastornos Esquizoafectivo, Trastornos Esquizofreniformes y T. del Ánimo con síntomas psicóticos.

En todo caso, debemos descartar previamente los T. Psicóticos causados por enfermedad somática, T. Psicóticos inducidos por tóxicos/medicamentos, los Episodios Psicóticos en los Síndromes de Abstinencia y los Trastornos Facticios - Simulación.

\section{MANEJO DEL PACIENTE PSICÓTICO}

En el abordaje del paciente con síntomas psicóticos es importante no caer en la confrontación directa; para este paciente los delirios y alucinaciones son tan reales como el resto de la realidad; debemos limitarnos a confirmar su presencia y tratar de ganar la confianza del paciente derivando su atención hacia síntomas más fáciles de aceptar (ansiedad, insomnio). No se trata de enfrentarse al delirio ni de darle la razón; hay que hacerle ver que comprendemos que su experiencia es real pero sugerirle que quizás haya otra explicación.

Se recomienda mantener una actitud empática y no crítica, realizar la entrevista sin impaciencia ni desconfianza, con preguntas y explicaciones breves y sencillas. El paciente psicótico tiene dificultades para organizar sus pensamientos de forma lógica y ajustada a la realidad y utiliza un lenguaje confuso y desconcertante para el entrevistador. De forma característica, éste experimenta sentimientos ambivalentes de interés y perplejidad, de temor y enojo o culpabilidad, que es preciso tratar de identificar y controlar de forma adecuada.

A partir de las entrevistas con el paciente y sus acompañantes es necesario obtener los datos básicos sobre su historia clínica: antecedentes personales y personales de trastornos psiquiátricos, episodios anteriores de ingresos y tratamientos previos, inicio y curso del episodio actual, trastornos del comportamiento más relevantes, etc. Es conveniente explorar y documentar siempre el riesgo suicida y de heteroagresividad.

En todos los casos se consideran criterios de ingreso:

1. Primer episodio psicótico, excepto en los casos seleccionados en los que es posible asegurar un correcto estudio y tratamiento ambulatorio.

2. Riesgo suicida y heteroagresividad, así como otras conductas que pongan en peligro la seguridad del paciente y del entorno.

3. Negativa a tomar la medicación.

4. Ausencia de contención familiar.

5. Efectos adversos graves de la medicación.

Con independencia de la derivación al especialista se debe ofrecer al paciente un tratamiento antipsicótico; será más fácil que lo acepte si se le informa de su capacidad para calmar la ansiedad y para hacerle sentirse mejor. Puede incluso ser necesario el uso de alguna benzodiacepina para disminuir el malestar del paciente. Dentro de los antipsicóticos conviene utilizar aquellos con un perfil de efectos adversos más favorable, para no provocar el rechazo del enfermo. En los últimos años los modernos antipsicóticos atípicos (risperidona (Risperdal $\left.{ }^{\circledR}\right)$, olanzapina (Zyprexa $\left.{ }^{\circledR}\right)$ ) se están imponiendo como tratamiento de primera línea en pacientes psicóticos, aunque fármacos más clásicos como el haloperidol (Haloperidol ${ }^{\circledR}$ ) siguen teniendo una validez incuestionable. Habrá que buscar siempre la dosificación más cómoda que permita a la vez asegurar el cumplimiento; por eso es mejor recurrir a una dosis única nocturna que permita aprovechar los efectos sedantes de estos fármacos. En la tabla 3 se esquematizan algunas de sus características farmacológicas. 
Tabla 3

\begin{tabular}{|l|l|l|l|l|l|l|l|l|}
\hline $\begin{array}{l}\text { Principio } \\
\text { activo }\end{array}$ & $\begin{array}{l}\text { Nombre } \\
\text { comercial }\end{array}$ & Potencia & Sedación & Extrapiramidalismos & Anticolinérgicos & Hipotensión & $\begin{array}{l}\text { Dosis } \\
\text { Equivalente }\end{array}$ \\
\hline $\begin{array}{l}\text { Antipsicóticos Típicos } \\
\text { Haloperidol }\end{array}$ & Haloperidol & Alta & + & +++ & + & + & 5 \\
\hline Pimocide & Orap & Alta & + & +++ & + & + & 2 \\
\hline Clorpromacina & Largactil & Baja & +++ & + & +++ & +++ & 100 \\
\hline Levomepromacina & Sinogán & Baja & +++ & + & ++ & +++ & 125 \\
\hline Tioridacina & Meleril & Baja & +++ & + & +++ & ++ & 125 \\
\hline & & & & & & & \\
\hline \\
Antipsicóticos Atípicos & & & & & & & & \\
\hline Clozapina & Leponex & Baja & +++ & + & +++ & +++ & 100 \\
\hline Olanzapina & Zyprexa & Alta & ++ & + & ++ & ++ & 5 \\
\hline Risperidona & Risperdal & Alta & + & + & + & ++ & 2 \\
\hline Quetiapina & Seroquel & Baja & ++ & + & + & ++ & 300 \\
\hline Amisulpride & Solian & Baja & + & + & + & + & 400 \\
\hline Ziprasidona & Zeldox & Alta & + & + & + & + & 80 \\
\hline Aripiprazol & Abilify & Alta & + & + & + & + & + \\
\hline
\end{tabular}

Si el paciente rechaza el tratamiento y se niega a acudir al especialista no debemos olvidar que se puede solicitar su traslado forzoso a la urgencia más cercana para evaluación psiquiátrica, apoyándose en la Ley de Enjuiciamiento Civil (artículo 763) que así lo especifica, con las máximas garantías de seguridad para el paciente y para los demás.

La mayor parte de las organizaciones no cuentan con protocolos establecidos para la identificación precoz de los empleados que padecen trastornos mentales graves y no reaccionan hasta que se produce una crisis originada por la gravedad de la alteración del comportamiento del trabajador afectado y de la repercusión de ésta en el ámbito laboral.

Cuando las circunstancias obligan a la dirección a tomar alguna decisión, esta puede sobreactuar por temor a las repercusiones negativas del empleadoposible enfermo mental con sanciones disciplinarias que con frecuencia excluyen y dañan más aún al afectado. En vez de esto se considera el siguiente procedimiento operativo (Brodsky y Epstein, 1996; Farid y Brodsky, 1996):

1. Confrontar al trabajador enfermo con las alteraciones que padece y sus consecuencias laborales, por parte de las personas más adecuadas como: médico de empresa, especialista de prevención de riesgos laborales, superior jerárquico, miembro del equipo de dirección, etc.

2. Valorar el grado de consciencia respecto de la alteración específica de conducta que presenta y su motivación para buscar la ayuda profesional que precisa.

3. Documentación de la "situación problema" con descripción de las alteraciones del comportamiento del trabajador como ha sido percibida por los compañeros y/o supervisores, representantes sindicales u otros intervinientes.

4. Comunicación escrita a la Dirección del Centro y al Servicio de Prevención de Riesgos Laborales solicitando valoración del estado de salud del trabajador presuntamente enfermo.

5. Citación por vía convencional al Servicio de Prevención, según el art. 22 de la ley 31/95 para realizar examen del estado de salud con las garantías habituales de confidencialidad, etc. y emisión de juicio clínico-laboral y grado de aptitud.

6. Si el trabajador no acude a la citación previa, se realizará citación escrita por carta certifica$\mathrm{da} /$ telegrama/burofax para reconocimiento médico obligatorio por sospecha de riesgo para él mismo o para terceros, tras la aprobación preceptiva del Comité de Salud y Seguridad del Centro. Si tampoco acude se realizará comunicación a Dirección-Gerencia para solicitar valoración y tratamiento médico involuntario por vía judicial.

7. En caso afirmativo el trabajador deber ser referido a su médico de referencia para ser 
evaluado por los profesionales sanitarios más convenientes.

8. Si el trabajador niega todo cambio conductual o la presencia de deterioro, se debería consultar con sus familiares, dado que el propio trastorno médico que padece puede impedirle asumir la responsabilidad de su propio tratamiento.

9. Siempre que sea posible, el trabajo del paciente se modificará para hacer posible que el trabajador siga trabajando.

10. En casos de máxima gravedad se activarán los protocolos de intervención urgente con intervención de los profesionales que marca la ley de Seguridad de Prevención de Riesgos Laborales.

\section{Mención especial merecen los Cuidados y Atención de Enfermería}

Para llevar a cabo un adecuado Plan de Cuidados de Enfermería, ha de seguirse el siguiente protocolo de actuación, y así obtener una valoración global del individuo:

\section{RECOGIDA DE DATOS}

1) Del paciente (verbalmente y no verbal).

2) De la familia.

3) Datos analíticos, exploración, informes médicos previos, etc.

4) De otros profesionales del sistema sanitario, que pudieron tratar anteriormente al paciente (trabajadores sociales, enfermeros comunitarios, terapeutas ocupacionales, etc.)

\section{APLICACIÓN DE LA TAXONOMÍA DE PRO- BLEMAS DE ENFERMERÍA Y GRADACIÓN DE LOS MISMOS.}

Los problemas de Enfermería (PE) más representativos dentro de los trastornos psicóticos agudos y transitorios son:

PE: Déficit de actividades recreativas.

PE: Trastornos del sueño.

PE: Deterioro en la adaptación.
PE: Ansiedad.

PE: Ineficacia del individuo para enfrentarse a los problemas.

PE: Trastornos del autoconcepto: Autoestima. Trastorno del autoconcepto: Identidad personal.

PE: Deterioro en la integración social.

PE: Aislamiento social.

PE: Afrontamiento ineficaz de la familia.

PE: Alteraciones de la alimentación.

PE: Déficit en el autocuidado: baño, limpieza, aseo...

PE: Alteración sensorial y perceptiva.

PE: Alteración en los procesos cognitivos.

PE: Alteración en el mantenimiento de la salud.

PE: Alteración en el mantenimiento y dirección del hogar.

Para planificar, ejecutar y evaluar las intervenciones de enfermería es importante establecer una relación de confianza. La confianza es la pieza fundamental para mantener una relación terapéutica consistente, de manera que se puedan planificar en común (paciente- personal terapéutico) las futuras intervenciones.

\section{Acciones de Enfermería}

- Presentarse al paciente.

- Explicarle el papel de cada uno de los miembros del equipo terapéutico.

- Mostrar el espacio físico y los distintos lugares donde se realizarán las diferentes intervenciones.

- Obtener la percepción que el paciente tiene de su problemática y los objetivos que pretende de su hospitalización o del tratamiento ambulatorio, facilitando una libre expresión de sentimientos. 
- Determinar las necesidades y conductas problemáticas del paciente.

- Exponer objetivamente y de forma sincera todo lo relativo al motivo de consulta o de ingreso, y todo lo referente a los problemas de complicación legal.

- Aceptar al paciente como persona, aunque no se apruebe su conducta patológica. bles.

- Fijar límites en aquellas conductas inacepta-
- Reforzar positivamente las conductas sanas.

- Evitar convertirse en el "único confidente" y no permitir que el paciente "regatee" para obtener favores especiales.

\section{Evaluación}

Siempre irá relacionada al Problema de Enfermería (PE) y basada en la confianza con el equipo terapéutico.

\section{PLAN DE CUIDADO DE ENFERMERÍA}
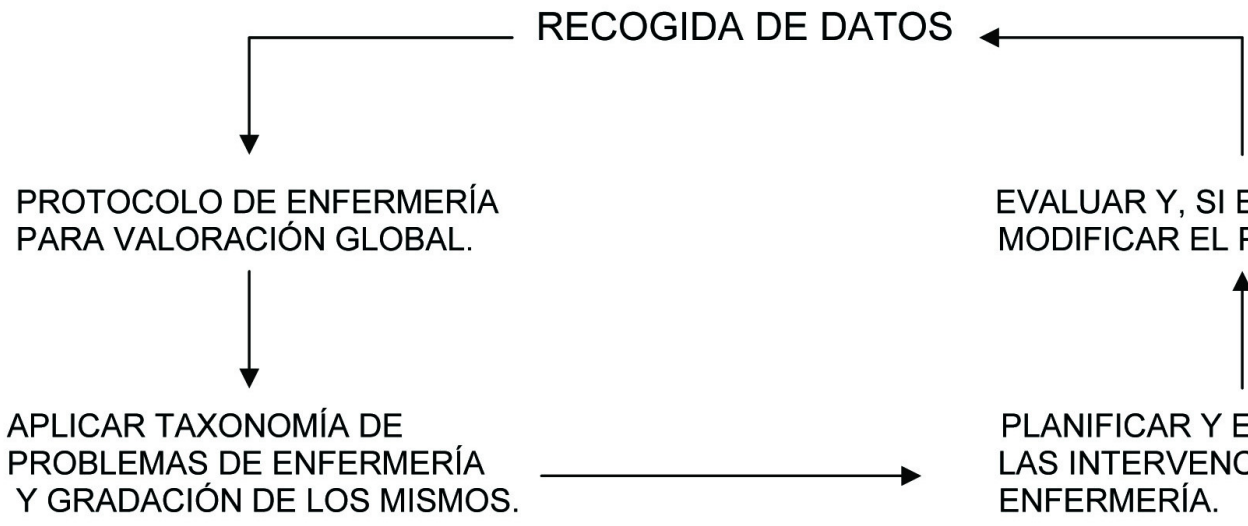

EVALUAR Y, SI ES NECESARIO, MODIFICAR EL PLAN.

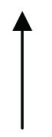

PLANIFICAR Y EJECUTAR LAS INTERVENCIONES DE ENFERMERÍA.

\section{El Trabajo Social en pacientes con Trastorno Psicótico.}

En el transcurso del proceso de enfermedad, la persona puede sufrir distintas dificultades sociales (familiares, económicas, laborales, vivienda, etc) para las que el trabajador social requiere intervenir. En dicha intervención social se debe tener en cuenta la propia demanda del paciente, el plan terapéutico elaborado, los propios recursos del paciente, así como los del medio sociocomunitario en el que vive.

Autores como Flower, Garety y Kupiers (1995) señalan algunas de las consecuencias que la experiencia psicótica puede tener para el paciente, tales como:

1) La persona puede llegar a creer que es extremadamente vulnerable a ser herido. Esta creencia estaría asociada a vivencias delirantes respecto a que otros puedan dañarle.

2) Creencia de que es altamente vulnerable a perder el control. Esto nacería de experien- cias de ser controlado por fuerzas externas o sentimientos de que no controlan sus propias acciones.

3) Creencia a estar condenado al aislamiento social. Esta vivencia puede nacer de experiencias reales de rechazo social o descalificación de otros cuando se conoce su condición de persona en tratamiento psiquiátrico.

4) La persona afectada puede llegar a construir una autoimagen totalmente negativa.

Por todo ello nos parece fundamental entender desde el trabajo social el impacto y las consecuencias que éstas tienen sobre el paciente. Este conocimiento facilita una mejor intervención social.

En general las personas que sufren esquizofrenia presentan décifits en alguna o en varias de las siguientes áreas que deben ser tenidas en cuenta a la hora de hacer una valoración integral del paciente, para poder valorar con ello la severidad de la pérdida del desempeño social: 
1) Autocuidados (deficiente manejo de su entorno, hábitos de vida saludable, etc.)

2) Autonomía (deficiente manejo del dinero, nula utilización del ocio y tiempo libre, dependencia económica y mal desempeño laboral).

3) Autocontrol (incapacidad de manejo de situaciones de estrés, falta de competencia personal, etc.).

4) Relaciones interpersonales (falta de red social, inadecuado manejo del ocio, falta de motivación e interés etc.).

5) Funcionamiento cognitivo (dificultades de atención, percepción, concentración y procesamiento de información, etc.). La valoración neuropsicológica especializada debe incluir funciones ejecutivas, atención-concentración, memoria y funcionamiento intelectual global.

6) Funcionamiento laboral (fracaso laboral, expectativas laborales desajustadas, faltas de hábitos básicos de trabajo y dificultades de manejo sociolaboral).

Estas discapacidades en el funcionamiento psicosocial conllevan a que muchos de estos pacientes presenten problemas en el manejo de las exigencias de la vida personal y social, y en el desempeño normalizado de roles sociales. Así mismo estas discapacidades, en interacción con diferentes factores y barreras sociales, (estigma, rechazo social, insuficiencia de recursos de atención y soporte social, etc.), pueden dar lugar a que muchas de estas personas estén en riesgo de desventaja social y marginación (aislamiento social, desempleo, falta de vivienda, exclusión social.)

Todo ello nos permite entender el importante papel que debe jugar la atención psicosocial, la rehabilitación social y el apoyo a la integración de este colectivo.

\section{Rehabilitación laboral y apoyo a la integración en el mundo del trabajo}

La integración laboral es una variable esencial del trabajo de rehabilitación en el paciente con trastorno mental grave, para facilitar su autonomía e integración social. Sin embargo, la mayoría de estas personas que padecen psicosis, están desempleados o excluidos del mundo laboral y presentan importantes dificultades para acceder y mantenerse en puestos de trabajo remunerado (Crespo Hervás, 2007).

Por lo tanto se necesitan programas de rehabilitación laboral que les orienten y les ayuden a adquirir aquellos hábitos laborales y habilidades sociales, que les permitan estar en mejores condiciones para acceder y manejarse en el mundo laboral. De hecho sólo el $25 \%$ de los pacientes con esquizofrenia tienen un empleo remunerado, la mayoría a tiempo parcial (Chinchilla Moreno, 2007).

Para ello es esencial la mejora del funcionamiento psicosocial (entrenamiento y recuperación de habilidades y capacidades) y apoyo a la integración social de estas personas, lo que ha de efectuarse desde un equipo multidisciplinar donde se entiendan dichas dificultades de manera integral. Este apoyo debe basarse en una concepción amplia y comprensiva de las personas con enfermedades mentales crónicas, debido a que la incapacidad por enfermedad mental tiene una alta repercusión social y por tanto una necesidad de readaptación.

En el caso de las personas con trastornos mentales graves y persistentes suelen producirse varias manifestaciones en el terreno laboral:

- Faltas al trabajo, desmotivación y disminución en el rendimiento laboral.

- Desobediencia e incumplimiento de las tareas propias del rol laboral.

- Conflictos interpersonales y conductas violentas en el trabajo.

- Falta de colaboración y aislamiento social.

- Pérdida de capacidad cognitiva.

\section{LOS COSTES DEL TRASTORNO MENTAL GRAVE}

Según estimaciones del Banco Mundial y la OMS, al menos el $25 \%$ de la "carga global de las enfermedades" se atribuye en la actualidad a los Trastornos mentales. Así, al evaluar la pérdida de años de vida ajustados por incapacidad (DALY), la esquizofrenia, el trastorno afectivo bipolar y la depresión mayor suman el $10,8 \%$ del total, lo que supone una pérdida comparable a la pérdida debida a la cardiopatía isquémica ( $9 \%)$.

Las discapacidades o deficiencias funcionales que limitan o dificultan la actividad personal se expresan mediante la Clasificación Internacional del Funcionamiento, de la Discapacidad y de la Salud 
(CIF, 2001), y el modelo de valoración de la Asociación Médica Americana, traducida y adaptada por el INSERSO (1994). Este último considera cuatro criterios básicos: actividades de la vida cotidiana (autocuidado, comunicación, sueño y actividades sociales $\mathrm{y}$ recreativas), funcionamiento social competente $\mathrm{y}$ responsable, concentración, persistencia y ritmo para realizar tareas; y capacidad de adaptación a situaciones estresantes, como en el trabajo.

De forma complementaria, la CIF evalúa daños en la estructura y funciones corporales, actividades y participación en relaciones sociales, a la vez que tiene en cuenta factores contextuales como la disponibilidad de apoyos y servicios profesionales, familiares, etc.

La esquizofrenia es la enfermedad mental más costosa y así por ejemplo se estima que representa el $2,5 \%$ de los gastos anuales en cuidados sanitarios en Estados Unidos. Además, se estima que los costes indirectos anuales acumulados por la pérdida de productividad de los pacientes es al menos cuatro veces superior a los costes directos, aparte de los costes indirectos para sus familiares y cuidadores.

Los pacientes con esquizofrenia constituyen el $10 \%$ de las personas enfermas con incapacidad permanente, cifre 10 veces mayor a que prevalencia a lo largo de la vida. Solo trabajan un pequeños porcentaje de pacientes con esquizofrenia (el 15\% en Estados Unidos y el 35\% en Inglaterra), lo que supone un gasto social muchos mayor que el del tratamiento directo del trastorno. La mayor parte de las personas con trastornos mentales graves están desempleados (entre el $60 \%$ y el $100 \%$ ) sobre todo si además pertenecen a minorías étnicas y tienen un bajo nivel educacional y laboral.

Estas altas tasas de desempleo dependen de la gravedad de la enfermedad mental, como de factores económicos y sociales (discriminación, políticas organizacionales, regulaciones de bienestar social, etc.). Incluso los profesionales sanitarios pueden ignorar la importancia del trabajo e incluso desaconsejar al paciente que trate de trabajar. No obstante, el derecho a trabajar está recogido en la Declaración Universal de los Derechos Humanos (1948) y en las Recomendaciones de las Naciones Unidas (1994) y en la Constitución Española (1978).

Los trastornos mentales pueden generar consecuencias en la conducta de los enfermos y repercutir de forma negativa en su actividad laboral. Así, pueden originar incapacidad temporal o permanente para la profesión habitual, permanente absoluta o gran invalidez, según los efectos correspondientes (Calcedo Ordoñez, 2005).

Los trastornos psicóticos crónicos han sido valorados en los tribunales laborales como causa de invalidez absoluta o total, según la gravedad de cada padecimiento individual, la frecuencia, duración e intensidad de los episodios agudos, la cronificación de los mismos, la existencia de complicaciones secundarias o la presencia de otros padecimientos asociados.

La mayor parte de los costes directos de la esquizofrenia se debe a la hospitalización psiquiátrica, que es significativamente más prolongada que la de la mayor parte de las enfermedades médicas generales. La pérdida de productividad representa el 50\% del coste de la enfermedad, mientras que la medicación constituye solo el $2 \%$ del coste total. La falta de empleo es el principal problema de muchas personas con trastornos mentales graves, lo que suele perjudicarles a través de la marginación, la pobreza y la exclusión social.

La prevalencia de la esquizofrenia a lo largo de la vida es alrededor del $1 \%$ y no se ha identificado ninguna población o cultura en la que no esté presente, con unos índices de prevalencia similares a través del mundo, aunque según los estudios de la OMS las tasas de recuperación y buen pronóstico son más altas en países en vías de desarrollo como India y Nigeria que en los países desarrollados. No obstante, la esquizofrenia es una enfermedad que se mantiene durante toda la vida a través de un diferente recidivas y con un frecuente empeoramiento a lo largo del tiempo.

La esquizofrenia puede comenzar a cualquier edad, aunque la mayoría de los inicios tienen lugar entre los 15 y los 54 años, con un máximo entre los 20 y los 26 años en los varones. En las mujeres la esquizofrenia se inicia 5 años después que en los hombre, y luego por encima de los 60 años. En todo caso, esta edad de inicio dificulta o aborta la posibilidad de desarrollar una productividad sociolaboral óptima. Actualmente está aumentando la incidencia y prevalencia de la esquizofrenia y se está adelantando la edad de inicio de los primeros episodios psicóticos por el consumo de alcohol y de otras sustancias de abuso por parte de los adolescentes.

Las personas que desarrollan esquizofrenia tienden a presentar, con mayor frecuencia, dificultades en sus relaciones sociales ya durante la infancia y la adolescencia, así como peores rendimientos acadé- 
micos y en el desarrollo del lenguaje, aunque con baja especificad y valor predictivo. Así, niños con un desarrollo temprano normal pueden padecer el trastorno a una edad de inicio más tardía (después de los 45 años), mientras que muchos niños con los déficit señalados no desarrollan la esquizofrenia. Se trata de una enfermedad con un componente genético sustancial, aunque también influyen las experiencias ambientales.

El modelo de neurodesarrollo de la esquizofrenia, es decir que la esquizofrenia es consecuencia de un defecto sutil en el desarrollo cerebral precoz, es la hipótesis patogénica más consistente, por desconexión o conexión errónea en la organización de circuitos neuronales de forma difusa que producen una afectación global del funcionamiento mental. (Weinberger y Murria, 1987). Esta hipótesis propone que se altera el desarrollo precoz del cerebro, aunque permanezca silente o poco sintomática hasta la aparición de los síntomas psicóticos. Además, estas personas tienen baja tolerancia al estrés, así como peor regulación afectiva y funcionamiento psicosocial.

La calidad del funcionamiento psicosocial depende de la consecuencia y/o mantenimiento eficaz de la capacidad para estudiar, trabajar, vivir independiente, mantener una relación de pareja estable y otras vinculaciones interpersonales significativas. Se denomina recuperación funcional la capacidad de recuperar el nivel de funcionamiento psicosocial previo al episodio más reciente de la enfermedad (Martínez Arán,y col. 2005).

Tras la experiencia de una descompensación clínica, es necesario pues evaluar tanto el grado de recuperación clínica de la enfermedad, como la recuperación psicosocial y el funcionamiento neurocognitivo, que pueden empeorar si se producen nuevos episodios, hay abuso comórbido de sustancias y según el tipo de fármacos neurolépticos utilizados.

La adaptación laboral depende no solo de los recursos instrumentales y emocionales del paciente, sino también del grado de complejidad y dificultad de realización de las tareas propias de cada empleo o profesión. Por ello están importante el análisis del trabajo o profesiograma específico como la evaluación integrada del paciente a lo largo de la evolución de la enfermedad.

Estos hechos dependen del déficit neurocognitivo de estos pacientes, que de forma consistente se han comprobado en los siguientes dominios:
1) Procesamiento atencional y de la información.

2) Razonamiento y solución de problemas.

3) Cognición social.

4) Velocidad de procesamiento.

5) Memoria y aprendizaje verbal y visual.

6) Memoria de trabajo.

La existencia de alteraciones sociales y laborales progresivas es una de las principales características para el diagnóstico de la esquizofrenia, en especial según criterios del DSM-IV. Disponer de información objetiva y fiable sobre las dificultades para adaptarse a los retos sociales, es fundamental en el proceso diagnóstico de la esquizofrenia. Las mayores dificultades se presentan para distinguir los déficits premórbidos, los pródromos de la enfermedad y la propia enfermedad. La disfunción sociolaboral en una o más áreas de actividad, como son el trabajo y las relaciones interpersonales, es un criterio diagnóstico de la mayoría de los trastornos mentales graves.

La calidad de vida de los enfermos con esquizofrenia empeora en todas sus dimensiones, especialmente en la actividad cognitiva, el desempeño de roles sociales y la productividad laboral, según la calidad de la asistencia clínica y de la disponibilidad de recursos para su rehabilitación, como hogares y talleres protegidos, hospitales de día, etc.

\section{ESQUIZOFRENIA: CARACTERÍSTICAS Y EVOLUCIÓN CLÍNICA}

A continuación se presentan los criterios diagnósticos del DSM-IV-TR para la esquizofrenia, un trastorno psicótico mayor. Sus particularidades básicas consisten en signos y síntomas característicos que han estado presentes durante un tiempo considerable en un período de un mes (o durante menos tiempo si se ha tratado satisfactoriamente), y con algunos signos del trastorno que han persistido durante por los menos 6 meses. Ningún síntoma único es patognomónico de esquizofrenia. Al contrario, los síntomas pueden afectar a diversos ámbitos psicológicos, como la percepción (alucinaciones), la ideación, el control de la realidad (ideas delirantes), los procesos del pensamiento (asociaciones laxas), los sentimientos (aplanamiento, afecto inadecuado), el comportamiento (catatonía, desorganización), la atención, la concentración y la motivación (abulia, intención y planificación alteradas). 
Estas características psicológicas y conductuales están asociadas con una variedad de alteraciones en el funcionamiento laboral y social. Aunque puede observarse un deterioro notable y la presencia de alteraciones en múltiples ámbitos del funcionamiento (p. ej., aprendizaje, autocuidado, trabajo, relaciones interpersonales y habilidades para la vida cotidiana), el trastorno se caracteriza por una gran heterogeneidad entre las distintas personas y una gran variabilidad en una misma persona a lo largo del tiempo.

Las personas esquizofrénicas también manifiestan una incidencia desproporcionadamente mayor de enfermedades médicas generales y una mayor mortalidad, en especial por suicidio, con una incidencia superior al $10 \%$ de los pacientes, según la Guía clínica para el tratamiento de la esquizofrenia.

A: Síntomas característicos: dos (o más) de los siguientes, cada uno de ellos presente durante una parte importante de un período de 1 mes (o menos si ha sido tratado con éxito):

1. Ideas delirantes.

2. Alucinaciones

3. Lenguaje desorganizado (p. ej., incoherencia)

4. Comportamiento catatónico o gravemente desorganizado

5. Síntomas negativos como aplanamiento afectivo, alogia o abulia

Nota: Sólo se requiere un síntoma del criterio A si las ideas delirantes son extrañas, o si las ideas delirantes consisten en una voz que comenta los pensamiento o el comportamiento del sujeto, o si dos o más voces conversan entre ellas.

B: Disfunción social/laboral: durante una parte significativa del tiempo desde el inicio de la alteración, una o más áreas importantes de actividad, por ejemplo el trabajo, las relaciones interpersonales o el cuidado de uno mismo, están claramente por debajo del nivel previo al inicio del trastorno (o, cuando el inicio es en la infancia o adolescencia, fracaso en cuando a alcanzar el nivel esperable de rendimiento interpersonal, académico o laboral).

C: Duración: persisten signos de la alteración durante al menos 6 meses. Este período de 6 meses debe incluir al menos 1 mes de síntomas que cumplan el criterio A (o menos si se ha tratado con éxito) y puede incluir los períodos de síntomas prodrómicos y residuales. Durante estos períodos prodrómicos o residuales los signos de la alteración pueden manifestarse sólo por síntomas de la lista del criterio A, presentes de forma atenuada (p. ej., creencias rara, experiencia perceptivas no habituales).

D: Exclusión de los trastornos esquizoafectivos y del estado de ánimo: el trastorno esquizoafectivo y el trastorno del estado de ánimo con síntomas psicóticos se han descartado debido a: 1) no ha habido ningún episodio depresivo mayor, maníaco o mixto concurrente con los síntomas de la fase activa, o 2) si los episodios de alteración anímica han aparecido durante los síntomas de la fase activa, su duración total ha sido breve en relación con la duración de los períodos activo y residuales.

E: Exclusión de consumo de sustancias y de enfermedad médica: el trastorno no es debido a los efectos fisiológicos directos de alguna sustancia (p. ej., una droga de abuso, un medicamente) o de una enfermedad médica.

F: Relación con un trastorno generalizado del desarrollo: si hay historia de trastorno autista de otro trastorno generalizado del desarrollo, el diagnóstico adicional de esquizofrenia sólo se realizará si las ideas delirantes o las alucinaciones también se mantienen durante al menos 1 mes (o menor si se han tratado con éxito).

Clasificación del curso longitudinal (menos de 1 año) desde el inicio de los primero síntomas de fase activa:

- Episódico con síntomas residuales interepisódicos (los episodios están determinados por la reaparición de síntomas psicóticos destacados): especificar también si con síntomas negativos acusados.

- Episódico sin síntomas residuales interepisódicos.

- Continuo (existencia de claros síntomas psicóticos a lo largo del período de observación); especificar si con síntomas negativos acusados.

- Episodio único en remisión parcial; especificar también si con síntomas negativos acusados.

- Episodio único en remisión total.

- Otro patrón o no especificado. 
De acuerdo con el DSM-IV-TR, los subtipos de esquizofrenia se definen a partir de síntomas predominantes en el momento de realizar la evaluación más reciente $\mathrm{y}$, por lo tanto, pueden cambiar con el tiempo. Estos subtipos incluyen: el tipo paranoide, en el que predominan la preocupación con ideas delirantes o alucinaciones auditivas; el tipo desorganizado, en el que destacan el discurso y el comportamiento desorganizados y el aplanamiento afectivo o inadecuado; el tipo catatónico, que se caracteriza por síntomas motores; el tipo indiferenciado, que es una categoría inespecífica a la que se recurre cuando no predomina ninguna de las otras características, y el tipo residual, en el que no se observan síntomas positivos destacados pero sigue existiendo alteración (p. ej., síntomas negativos o síntomas positivos en una forma atenuada). Aunque las repercusiones en el pronóstico o el tratamiento de estos subtipos varían, el tipo desorganizado tiende a ser el más grave y el tipo paranoide el menos grave.

Otros trastornos mentales y enfermedades médicas generales pueden ser comórbidas con la esquizofrenia. Junto con las enfermedades médicas generales, el trastorno comórbido más frecuente sería el trastorno por abuso de sustancias. Con frecuencia, entre las sustancias de abuso se incluye el alcohol; estimulantes como la cocaína y las anfetaminas; la nicotina, el cannabis, la fenciclidina y el LSD. Este tipo de comorbilidades pueden empeorar el curso de la enfermedad y complicar el tratamiento. Las personas con esquizofrenia también pueden experimentar síntomas de otros trastornos mentales, sobre todo depresión, pero también síntomas obsesivo-compulsivos, preocupaciones somáticas, síntomas disociativos y otros síntomas del estado de ánimo o ansiedad.

Las personas con esquizofrenia tienen mayor riesgo de padecer aquellas enfermedades asociadas con malos autocuidados o internamiento (p. ej., tuberculosis, hepatitis), consumo de sustancias (p. ej., enfisema y otras patologías asociadas al consumo de tabaco, enfermedad relacionada con el VIH) y trastornos del movimiento inducidos por antipsicóticos. Algunas personas esquizofrénicas manifiestan prolidipsia inducida por psicosis, que puede causarles hiperhidratación hipotónica o hiponatremia.

Estudios recientes de seguimiento de personas con esquizofrenia demuestran que los actuales tratamientos disponibles han mejorado el curso de la enfermedad a largo plazo de muchos pacientes, junto con los efectos beneficiosos de la desinstitucionalización.
Aunque la esquizofrenia sea un trastorno mental grave no es menos cierto que su evolución clínica y la calidad de vida de las personas afectadas se caracterizan por una alta variabilidad. Así al cabo de 30 años:

- El 25\% se recuperan completamente.

- El 35\% mejora considerablemente, con una vida relativamente independiente.

- El 15\% mejora parcialmente con gran número de recaídas y necesita una gran red de apoyo social.

- El 10\%, permanece hospitalizado, por sintomatología psicótica crónica.

- El 15\% fallece, la mayoría por suicidio. La mortalidad de los pacientes con esquizofrenia es tres veces superior a la de la población general.

La esquizofrenia es una enfermedad mental grave (Makenna y cols. 2007; Hirch y Weinberger, 2003), que con frecuencia tiene un curso crónico o recurrente con brotes sucesivos, en la que el inicio de los síntomas psicóticos suele tener lugar en la adolescencia y el inicio de la edad adulta. El comienzo de la enfermedad suele ser más agudo en las mujeres, mientras que en los hombres suele ser insidioso. En la mayoría de los casos, antes del primer episodio psicótico se observan diferentes síntomas prodrómicos, con alteraciones del comportamiento y deterioro de las actividades sociales, académicas y laborales, síntomas afectivos, ansiedad, alteraciones del sueño, etc.

Con frecuencia, el inicio es agudo tras un estrés psicosocial como el académico o el laboral. Luego, la presencia de situaciones estresantes puede facilitar la aparición de nuevas recaídas. Tras el primer episodio algunos pacientes se recuperan y tienen un funcionamiento normal durante muchos años.

Alrededor del 20-30\% de los pacientes con esquizofrenia tienen una buena evaluación clínica en los 10 años siguientes tras la primera hospitalización psiquiátrica.

El 50\% de los enfermos evoluciona mal, con reiteradas hospitalizaciones, exacerbación de los síntomas, alteración del estado de ánimo e intentos de suicidio que llegan a consumarse en el $15 \%$ de los casos.

La tabla 4 recoge unas características clínicas indicativas del pronóstico de la esquizofrenia. 
Tabla 4

\begin{tabular}{|l|l|l|}
\hline & \multicolumn{1}{|c|}{ Buen pronóstico } & \multicolumn{1}{c|}{ Mal pronóstico } \\
\hline Inicio & Agudo & Insidioso \\
\hline Factores precipitantes & $\mathrm{Si}$ & No \\
\hline Edad inicio & $>30$ años & Más jóvenes \\
\hline Estado civil & Casado & Soltero, divorciado, viudo \\
\hline Adaptación socio-laboral previa & Buena & Mala \\
\hline Síntomas afectivos & Depresión & Afecto embotado \\
\hline Antecedentes psiquiátricos familiares & Trastornos afectivos & Esquizofrenia \\
\hline Apoyo socio-familiar & Bueno & Malo \\
\hline Recaídas & Pocas o ninguna & Múltiples \\
\hline Síntomas & $\begin{array}{l}\text { Positivos (alucinaciones y } \\
\text { delirios) }\end{array}$ & $\begin{array}{l}\text { Negativos (abulia, anedonia, autismo, } \\
\text { apatía o embotamiento afectivo) }\end{array}$ \\
\hline Tratamiento & $\begin{array}{l}\text { Buena respuesta y } \\
\text { colaboración }\end{array}$ & $\begin{array}{l}\text { Mala respuesta al tratamiento y } \\
\text { colaboración. }\end{array}$ \\
\hline
\end{tabular}

El 25\% presenta síntomas moderados, con exacerbaciones episódicas. La evolución durante los 5 primeros años tras el diagnóstico indica el curso clínico del paciente: a mayor número de recaídas peor pronóstico. Esta fase también se llama período crítico.

La esquizofrenia de inicio tardío, después de los 45-50 años, en solo el 20\% de los casos se caracteriza por los síntomas paranóides, predominar en mujeres (con un riesgo doble que en varones) y asociarse con afectaciones sensoriales y varias anomalías cerebrales, en comparación con grupos de controles de la misma edad. Estos pacientes suelen presentar rasgos previos de personalidad esquizóide y paranóide. Las modernas técnicas de neuroimagen constatan en la SPECT hipoperfusión de predominio frontotemporal, enlentecimiento en el EEG y atrofia cortical en la Resonancia Magnética Cerebral. Con alguna frecuencia ( $1 / 3$ de ellos) estos pacientes evolucionan hacia la demencia; sea tipo Alzheimer, degeneración del lóbulo frontal o tipo mixto, asociada esta última a varios factores de riesgo cardiovasculares. En todos los casos debe priorizarse el tratamiento etiológico, con criterios preventivos, teniendo en cuenta los cambios farmacocinéticos y farmacodinámicos en las personas de edad avanzada.
Los primeros síntomas que presentan estos pacientes suelen ser de tipo conductual, por deterioro de sus recursos adaptativos, y especialmente en el trabajo, con frecuentes conflictos interpersonales y empeoramiento en el rendimiento laboral.

\section{LA PERSONA CON ESQUIZOFRENIA EN EL TRABAJO}

Según Crespo Hervás (2007): "La mayoría de las personas con esquizofrenia pueden trabajar...", sean trabajos competitivos o empleos protegidos, porque según esta autora les mejora la autoestima, ayuda a los enfermos a recuperarse, les permite establecer nuevas relaciones sociales y refuerza un sentimiento de pertenencia a la comunidad, además de incrementar los ingresos de la familia y promover una ordenación temporal. Se consideran recomendables empleos poco estresantes y bien estructurados que proporcionen una estructura y un orden diarios a la vida, les permitan establecer relaciones interpersonales estables y generen un sentimiento de pertenencia, así como integración de la persona enferma en una comunidad de personas sanas (Crespo Hervás, 2005).

Fuera de las descompensaciones agudas se ha contrastado el efecto beneficioso de la actividad laboral sobre el curso de los trastornos mentales graves, cuando se realiza un tratamiento óptimo. 
Es importante tener en cuenta el estadio del proceso esquizofrénico en el que se encuentra la persona afectada:

1) Estadio prodrómico: se caracteriza por dificultades para el aprendizaje académico (déficit de concentración, memoria, etc.), pérdida de interés e iniciativa y tendencia al aislamiento social, síntomas inespecíficos que pueden interferir e incluso impedir el estudio y/o el trabajo eficiente. La fase prodrómica suele durar entre 2 y 5 años: durante este tiempo la persona presenta síntomas inespecíficos (ansiedad, insomnio, depresión, etc.) así como un progresivo deterioro funcional $\mathrm{y}$ social.

2) Estadio inicial: puede ser un inicio abrupto mediante crisis o brotes alucinatorios delirantes, o bien cursar con un inicio lentamente progresivo, de manera tórpida y poco llamativa. En el primer caso suele tratarse de un cuadro tan aparatoso que se produce el ingreso psiquiátrico, mientras que en el segundo puede pasar desapercibido más tiempo y el enfermo privarse de un tratamiento eficaz. Durante la fase psicótica (síntomas positivos como alucinaciones y delirios) los pacientes son incapaces de cuidar de sí mismos.

3) Estadio conclamado: ya hay síntomas típicos de las distintas formas clínicas: paranoide, bebefrénica, catatónica y simple, pero con variables grados de afectación a lo largo del tiempo.

4) Estadio de remisión o estabilización: en el que la psicoterapia y la psicofarmacología pueden mejorar el bienestar personal y prevenir otros brotes de la enfermedad, que pueden durar varios años. Estos pacientes se mantienen asintomáticos o con síntomas no psicóticos (Estadio de Estabilidad).

5) Estadio Terminal o irreversible en el peor de los casos. Se habla de resistencia al tratamiento cuando no hay una mejoría clínica significativa a dos o más neurolépticos durante 6 ó más semanas a dosis terapéuticas adecuadas. La esquizofrenia residual o deficitaria se caracteriza por el predominio de síntomas negativos primarios y resistentes al tratamiento, como la abulia y el aplanamiento afectivo.

La edad precoz de inicio, el grado de deterioro cognitivo y la intensidad de los síntomas negativos y la presencia de comorbilidad neurológica condicionan un peor rendimiento académico y un funcionamiento social deficiente, que con frecuencia impiden concluir los estudios académicos en algunos casos de esquizofrenia.

En el caso de una persona con esquizofrenia en fase prodrómica con una afectación leve de la personalidad y síntomas discretos, o en períodos en los que se ha alcanzado una remisión completa, tras un episodio agudo, puede mantenerse un desempeño laboral adecuado, aunque se precisa una supervisión eficaz para prevenir riesgos para el paciente, así como para los demás.

La esquizofrenia es una enfermedad que cursa con exacerbaciones agudas y remisiones en las que el paciente puede funcionar de forma adecuada durante algún tiempo, No obstante, cada exacerbación de la enfermedad conduce a mayor deterioro residual. Después de 5 años de enfermedad un tercio de los pacientes tienen una buena recuperación clínica: Hay un subgrupo de personas con esquizofrenia que evolucionan favorablemente, tras padecer episodios esquizofréniformes (menos de 6 meses de duración).

En los casos de esquizofrenia con persistencia de síntomas psicóticos interepisódicos, con o sin síntomas negativos, de tipo desorganizado, catatónico y simple, con dificultades graves en las relaciones intepersonales y laborales, y déficits cognitivos significativos, pueden ser, en ocasiones, invalidadas para trabajos normalizados.

Las disfunciones cognitivas en la esquizofrenia, dimensión principal de la enfermedad, son poderoso predictores clínicos, especialmente relacionados con el ajuste social. Destaca de forma consistente las disfunciones ejecutivas frontales (Weinberger y col. 1986), aunque estudios posteriores con pacientes bipolares indican que la disfunción cortical prefrontal se asocia a psicosis en general. Varios estudios confirman los déficits atencionales, en memoria de trabajo, en fluidez verbal y en el procesado de información en los pacientes con esquizofrenia, que en parte preceden al inicio de los síntomas clínicos, pero que se agravan a lo largo de la evolución de la enfermedad.

La edad de inicio tardío, el buen ajuste premórbido, mantener relación matrimonial, actividad laboral y mejores relaciones sociales son factores de buen pronóstico en la esquizofrenia. La esquizofrenia de inicio juvenil, con predominio de síntomas negativos, antecedentes familiares del espectro esquizofré- 
nico y ausencia de respuesta al tratamiento neuroléptico, impide, en mayor medida, desempeñar una actividad laboral satisfactoria, afectando a los familiares que tienen que reajustar sus actividades para cuidarlo y generando elevados costes sociales.

Frecuentemente en un medio laboral competitivo los casos de evolución tórpida acaban por no poder realizar un trabajo eficaz ni integrarse suficientemente a nivel social. En concreto la sintomatología negativa y el deterioro global esquizofrénico condicionan impedimentos definitivos para incorporarse a un trabajo normalizado, presentando una incapacidad laboral permanente.

\section{ABORDAJE PRÁCTICO DEL ENFERMO CON ESQUIZOFRENIA}

Dada la habitual falta de conciencia de enfermedad del enfermo con esquizofrenia es frecuente que este necesite ser motivado y acompañado para poder llegar a consultar por familiares y/o compañero de trabajo, habitualmente por conflictos interpersonales y las consecuencias negativas en su desempeño laboral.

Además, el paciente es muy vulnerable al estrés, incluso frente a situaciones habituales del trabajo y de la familia. De forma típica, el paciente pierde iniciativa y motivación, se muestra desganado, es menos efectivo en el desempeño de sus tareas y pierde la autocrítica. En consecuencia, suele cometer errores o llevar a cabo conductas inapropiadas, sin conciencia de responsabilidad y negación de sus implicaciones. De forma gradual, la conducta del paciente esquizofrénico se hace desorganizada e inadaptada, hasta poder llegar a ser caótica, en una descompensación aguda o cuando alcanza suficiente gravedad en un curso tórpido: El paciente se ha ido mostrando desconfiado y retraído, huraño e hipervigilante, con amenazas inadecuadas y comportamientos extraños e incluso hostiles. Así por ejemplo, según los informantes, la persona se mantiene aislada, nos mira de forma rara, anda solo, dice cosas extrañas como que le expían los compañeros, que todos están en contra suya, que le miran y hablan de él de forma despectiva...

En este estadio la familia suele percatarse también de que el paciente "ya no es el mismo, no habla como antes, parece un zombi, etc." y con frecuencia comunica a su médico las alteraciones que presenta en casa. Si el paciente no acepta consultar por propia iniciativa, al confrontarle con los cambios de conducta que ha experimentado deberá promoverse la consulta involuntaria por vía judicial de la forma más rápida y segura posible.
En el tratamiento del paciente psicótico se distinguen las siguientes fases:

1) Fase aguda o de brote, con el paciente internado y protegido con fármacos antipsicóticos en dosis eficaces. Se debe informar a los familiares sobre los riesgos de que el enfermo pueda autolesionarse o agredir a terceros.

2) Fase subaguda o de recuperación, de 6 a 12 meses, comienza con cierta conciencia de enfermedad y capacidad de cooperación, así como incremento de la angustia por la percepción del daño mental propio. El paciente debe concurrir a un centro de día organizado como comunidad terapéutica integrado.

3) Fase crónica o de remisión, el paciente debe seguir tomando la medicación, a la vez que intenta reconectarse con sus actividades habituales. Dadas la dificultades para integrar la experiencia psicótica y el alto riesgo de abandonar el tratamiento debe controlarse estrechamente la adherencia al tratamiento para prevenir las recaídas y el deterioro residual.

El tratamiento óptimo de la esquizofrenia requiere la integración de la farmacoterapia y de las intervenciones psicosociales, con una efectividad superior a la de su suma simple, ya que cada uno de ellos actúa en ámbitos diferentes y se potencian mutuamente, de forma individualizada.

Desde la introducción de la Clorpormazina en los años 50 se ha logrado mejorar el control de los síntomas psicóticos y prevenir las recaídas en muchos pacientes con esquizofrenia, aunque pueden producir ciertos efectos secundarios característicos. El factor diferencial fundamental es el grado de adherencia terapéutica. El incumplimiento del tratamiento es de hasta el $70 \%$ de los pacientes a partir del segundo año trascurrido después del período de hospitalización (Fuller Towey, 2006). Los principales factores que le condicionan son:

1) La falta de conciencia de enfermedad mental (anosognosia).

2) La negación de la misma.

3) Efectos secundarios de la medicación.

4) Alianza terapéutica defectuosa.

5) Creencias delirantes respecto a la medicación.

6) Deterioro de funciones ejecutivas.

7) Creencias erróneas sobre la medicación. 
Estos factores de riesgo orientan a las posibles intervenciones para mejorar la adherencia al tratamiento:

1) Mejorar la calidad de las relaciones asistenciales.

2) Intervenir con programas psicoeducativos sobre la enfermedad, la relación riesgo-beneficios, sobre el tratamiento, etc.

3) Facilitar el tratamiento a través de simplificar la posología, administración de medicación depot, etc.

En todos los casos, el trabajar con esperanza es el predictor más importante de la mejoría posterior e incluso de la recuperación completa, hasta en más del $50 \%$ de los casos afectados, a largo plazo, si reciben un tratamiento adecuado. Según la OMS (1980) el tratamiento debe orientarse a las tres dimensiones: deterioro, incapacidad y handicap. El deterioro incluye los síntomas principales de la enfermedad. La incapacidad se refiere a las dificultades con las actividades de la vida cotidiana, las habilidades sociales, familiares y profesionales. El handicap es la desventaja económica, la estigmatización y la exclusión social.

Los tratamientos psicosociales de los pacientes con esquizofrenia incluyen la psicoteratpia, tanto individual como grupal, el adiestramiento en habilidades sociales y la rehabilitación profesional. Esta última modalidad de tratamiento facilita la reincorporación de los pacientes a la comunidad como se promulgó en el Acta de Rehabilitación de 1973, que insta a los servicios sociales estatales a priorizar la contratación de personas con una incapacidad psiquiátrica.

\section{Terapia ocupacional}

Sea en talleres protegidos, clubes de trabajo y programas de empleo de tiempo parcial, se trata de diversos métodos para ayudar a los pacientes a recuperar habilidades o desarrollar otras nueva, contar con alguna remuneración económica y facilitar su reinserción social.

\section{Recomendaciones en caso de amenaza de conduc- ta violenta}

Aunque la mayoría de enfermos mentales no son violentos, la conducta violenta es 15 veces más frecuente entre los enfermos mentales que en la población general, aunque la contribución total a la violencia por parte de las personas con enfermedad mental grave es menor del $5 \%$, según la revisión de Uriarte (2005).

En especial, la conducta violenta es más frecuente en pacientes varones jóvenes con esquizofrenia, trastornos afectivos y trastornos graves de la personalidad, sobre todo si no realizan el tratamiento y si se asocian con el abuso, dependencia o intoxicación con sustancias adictivas.

\section{Estrategias de intervención}

\section{1) Técnica de desactivación o desescalada.}

En primer lugar debe realizarse la intervención verbal para reducir la tensión: dirigirse al paciente de forma tranquila y no provocadora, intentar establecer una conversación clarificadora y ofrecerle otras alternativas más eficaces, así como tomar la medicación de forma voluntaria.

\section{2) Intervención involuntaria.}

Con empleo de contención física, sujeción mecánica e intervención farmacológica, si existe un riesgo elevado para el paciente o para otras personas.

3) Una vez sedado, el paciente necesita vigilancia continua y realizar los exámenes médicos que hagan posible el diagnóstico clínico y el tratamiento eficaz.

Las conductas violentas de los enfermos con esquizofrenia se caracterizan por ser: absurdas, de una crueldad brutal, inmotivadas e inesperadas y dirigidas contra las personas del medio familiar y social más próximo. Posteriormente destaca la ausencia de sentimientos de culpa, la indiferencia afectiva y el aislamiento social extremo.

La criminalidad de estos pacientes viene determinada por varios factores: características de personalidad, biografía, patología dual, incumplimiento terapéutico en varones jóvenes. Estas conductas violentas son muy difíciles de prevenir, dada la desorganización mental del paciente y la baja conciencia de enfermedad, pero con frecuencia existen amenazas y signos de amenaza de agresión que es necesario tener en cuenta.

\section{Intervención adecuada en situaciones de crisis}

Como dicen de forma magistral Mac Kinnon y Michels (1973): "En todas las situaciones de urgen- 
cia - psiquiátricas, civiles, militares y otras - la gente no sabe qué hacer. La función más importante del médico está en producir la impresión de que él sí, sabe lo que hay que hacer, y en ayudar al paciente y a los que le acompañan a desarrollar una idea clara de lo que ellos pueden hacer".

\section{PARANOIA O TRASTORNO DE IDEAS DELIRANTES PERSISTENTES}

Es un término utilizado por primera vez en 1863 por Kahlbaum, que cursa de forma estable, en ausencia de alucinaciones y deterioro de la personalidad con una prevalencia del $0,025 \%$, la edad media de inicio es de 40 años, desde los 18 a los 90, con un ligero predominio del sexo femenino.

Se le reconoce una etiología multifactorial, con mayor prevalencia entres familiares de afectados, se asocia con 7 factores de riesgo según Cameron (1959): Aislamiento social, antecedente de trato sádico que se anticipa en el futro, situaciones de frustración que aumentan la desconfianza y la suspicacia, la envidia y los celos, o disminuyen la autoestima, la deprivación estimular y de información respecto del medio social.

El término paranoia deriva del griego "para nous" que significa etimológicamente "tener la mente fuera de uno mismo", se utilizó en Grecia como sinónimo de "locura" o enfermedad mental, para indicar alteraciones graves del pensamiento. El delirio se define como: "un error patológico del juicio en relación con la realidad, incorregible ni por la crítica ni por la experiencia".

Kretschmer (1927) propuso que la paranoia se desarrolla sobre personalidades hipersensibles, con sentimientos de inadecuación y de autoimportancia no reconocida, tras sufrir alguna "experiencia clave" que precipita el desarrollo psicótico sobre un estado de ánimo previo característico (Wahnstimmung) que incluye ansiedad, perplejidad y sensación de crisis inminente: cuando el delirio cristaliza se instaura una vivencia nueva de revelación y de certeza.

Kraepelin (1920) describió este trastorno como "el desarrollo insidioso de un sistema permanente y firme de delirios que surge en razón de causas internas, y que está acompañado por la perfecta preservación de pensamiento, voluntad y acción claros y ordenados; "además de la ausencia de alucinaciones, no se aprecia deterioro de la personalidad, a pesar del curso crónico de la enfermedad.

Sin embargo Kolle (1931) estudió 66 casos de 1 a 44 años y resultó que el $24 \%$ de ellos requería atención hospitalaria permanente; además de que entre sus familiares la prevalencia de esquizofrenia era mayor que en la población general, concluyendo que salvo las de etiología orgánica, las psicosis paranoides crónicas pertenecen al grupo de las esquizofrénicas. Varios autores que consideran que la conducta paranoide constituye una dimensión o continuum psicopatológico, que incluye la personalidad paranoide, la esquizofrenia y el estado paranoide involutivo, entre otros estados paranoides.

El carácter paranoide se caracteriza por los siguientes rasgos:

1) Desconfianza y susceptibilidad

2) Hipertrofia del yo (orgullo).

3) Afecto dominante: la pasión.

4) Psicorigidez del juicio.

5) Mecanismos defensivos rígidos: proyección y negación.

Kraepelin (1895) ha descrito las siguientes dimensiones de la respuesta paranoide.:

1) La principal es la afectiva: miedo, orgullo, culpa, odio, desconfianza, hiperestesia perceptiva interpersonal: intenso sufrimiento, y disfunción emocional y relacional.

2) La del pensamiento, de forma secundaria: disociación extrema con idealización propia y diabolización del otro convertido en enemigo y construcción del delirio por mecanismo de proyección.

3) La dimensión de la voluntad.

4) La dimensión de la acción: por rígida coherencia interna, aunque sobre premisas falsas, justifica "el paso al acto" de forma autocomplaciente y megalomaniaca.

Se han descrito los siguientes factores de riesgo para el desarrollo de paranoia: condiciones internas y externas:

1) Desgracias repetidas (incluso a través de generaciones sucesivas), enfermedades graves y contacto precoz con la muerte (sensibilización postraumática).

2) Persecuciones reales, humillaciones, limitaciones e infravaloraciones corporales (la terri- 
ble mirada que tan bien conocen los negros...) y la indiferencia hostil ("como si uno no existiera").

3) Quiebra del soporte identificatorio, sea por ausencia de función paterna (padre alcohólico humillado, padre idolizado, sin interés por sus hijos, o sólo en función de sus propios intereses) y/o por simbiotización patológica materna.

El patrón de conducta tipo paranoide (o el descenso al infierno) descritos por Olievenstein (1993) se caracteriza por:

1) Perfil activo caracterizado por el continuo empeño de verificar y cosechar agravios y malos tratos que le permitan justificar su estatuto de víctima.

2) Insaciable búsqueda de contacto con el otro (perseguidor-perseguido), como intento de control de la angustia de destrucción personal (parasitismo hostil).

3) Estilo cognitivo caracterizado por la suspicacia y por un razonamiento basa en indicios de significados ocultos. Regresión narcisista y predominio de la identificación proyectiva sobre el juicio de realidad.

4) Incluye de forma manifiesta la bestia acorralada y peligrosa, y de forma latente a la criatura desamparada y rechazada de forma hostil; es el fruto diabólico del mal.

Se ha descrito el imperceptible desarrollo paranoico a través de una serie de etapas:

1) No se nace paranóico, la paranoia se construye en un largo proceso de incubación, a golpe de adversidades de la vida, hasta llegar a configurar la frágil identidad del paranoico, mal disimulada por su adicción caníbal al poder (megalomanía).

2) Larga secuencia de fracasos, desgracias y traumatismos acumulados, median en un proceso de hipersensibilidad afectiva interpersonal, hasta el adulto despersonalizado, desvalorizado, incapaz de experimentar y de dar placer, de "ser reconocido" en la relación con el otro.

3) Las intensas angustias de daño vital (desindividuación, depresión) promueven una regre- sión-desorganización estructural con mayor despersonalización y depresión, que se gestionan con mecanismos primitivos (disociación, proyección, negación), como intentos ineficaces de manejar insoportables angustias de destrucción personal.

Las características principales del "enfoque paranoide de la vida" son según Swanson y cols. (1970):

1) Pensamiento proyectivo.

2) Hostilidad en lugar de ansiedad y conducta violenta.

3) Suspicacia hipervigilante.

4) Miedo a la pérdida de control y autonomía en la vida, como en una contienda continua.

5) Autorreferencia megalomaniaca.

6) Ideas delirantes sistematizadas, persistentes e inconmovibles.

7) Grandiosidad paranoide.

Características que median en frecuentes conflictos personales, comportamientos abusivos y hostiles, así como en un elevado malestar familiar y sociolaboral, hasta provocar complicaciones secundarias como separaciones o divorcios e incluso la pérdida de empleo.

En la psicoterapia de los enfermos se han destacado los siguientes aspectos:

1) Ayudar al enfermo a salvar las apariencias y a mejorar su autoestima.

2) Evitar despertar mayor desconfianza: claridad.

3) Ayudar al enfermo a mantener una percepción de control.

4) Estimular la verbalización de la hostilidad y prevenir, así, la conducta agresiva.

5) Evitar aproximaciones físicas y emocionales amenazadoras (gran necesidad de distancia).

6) Atención a la propio contratransferencia: tomar en serio los miedos percibidos de sufrir violencia y no "hacerse el valiente".

\section{EL PACIENTE PARANOIDE EN EL TRABAJO}

A diferencia de otros pacientes psicóticos destaca por su aspecto correcto, rígido y tenso, y su discurso normal, salvo que se aborde el tema delirante 
del paciente. De forma característica, éste presenta un delirio crónico de temática persecutoria, querulante, megalomaníaca, celotípica, erotomaníaca o hipocondríaca, con coherencia lógica y claridad de conciencia.

Así, el paciente se cree víctima de persecuciones en el trabajo, asegura que existe un complot contra él, etc., de forma racional pero sobre unos supuestos básicos falsos en relación con determinados sucesos. Como dicen Mac Kinnon y Michels (1973): "Todo delirio paranoide contiene algún núcleo de realidad".

El delirio incluye los tipos de ideas ya referidos, de forma bien organizada, no existen alucinaciones ni otras alteraciones del juicio de realidad, una afectividad conservada y una personalidad no deteriorada, aunque patológica.

Con estos pacientes no se debe utilizar la argumentación lógica para intentar confrontarles con la realidad ni para rebatirles sus creencias falsas. Tampoco se les puede seguir la corriente y reforzar así su delirio. Al contrario, se deben tomar en serio las amenazas que pueden hacer hacia otras personas... porque al final la persona paranoide termina por actuar contra otros o contra sí mismo, si no se les trata de forma adecuada. En estos casos está indicado el ingreso en centro psiquiátrico, sea de forma voluntaria o involuntaria, mediante autorización judicial. Estas gestiones para la hospitalización han de tratarse abiertamente, con el paciente bajo constante observación, hasta que pueda realizarse.

Superada la crisis, una buena adherencia terapéutica y la posibilidad de conservar relaciones mutuamente satisfactorias y los refuerzos positivos que proporciona el empleo, son aspectos claves de un buen pronóstico, a pesar de la gravedad del padecimiento.

\section{CONCLUSIONES}

La capacidad de trabajar es una de las funciones sanas de la personalidad que depende de varios factores como el grado de motivación y la competencia técnica para realizarlo, el tipo de trabajo y la existencia de patologías médicas o psicológicas que interfieren con el ejercicio de la actividad laboral. Es decir, que la competencia conductual del paciente no depende directamente del trastorno mental que padezca en sí mismo, sino del grado de afectación y la persistencia de las funciones mentales que resulten alteradas por tales factores intervinientes en cada persona a lo largo del tiempo.
Aunque el artículo 35.1 de la Constitución Española establece que los ciudadanos tienen el derecho y el deber de trabajar, derecho a la libre elección de profesión u oficio y a la promoción por medio del trabajo, se trata de una capacidad jurídica general que, para llevarse a efecto en cada caso requiere también determinadas aptitudes funcionales para la práctica necesaria en cada trabajo. El desempeño de cualquier actividad laborar requiere suficiente motivación, dedicación y competencia, que han de valorarse en las condiciones reales de cada empleo y en cada personas. Es importante valorar no solo las cuestiones de diagnóstico y tratamiento, sino también las capacidades del afectado para cada empleo específico.

En consecuencia, al hacer el diagnóstico es conveniente utilizar los criterios del DSM IV-TR (2002) o de la CIE (1996) para definir el trastorno y hacer el diagnóstico de la deficiencia, alteración o pérdida funcional que puede interferir en actividades de la vida diaria como el autocuidado e higiene personal, comunicarse con los demás, ser capaz de vivir de forma independiente, etc. El tipo y el grado de deterioro varían de forma notable entre pacientes con un mismo diagnóstico y dentro de la misma persona a lo largo de la evolución del trastorno mental que padece. En consecuencia es conveniente evaluar las consecuencias del trastorno (el grado de discapacidad) y no solo su naturaleza (Carrasco Gómez y Maza Martín, 2005).

En las enfermedades que cursan en brotes, éstas deber ser evaluadas en los períodos intercríticos y una vez optimizado el tratamiento, haber alcanzado el nivel máximo de funcionamiento global y la estabilidad clínica. En este sentido se recomienda utilizar instrumentos diagnósticos tales como: Escala de Actividad Global (Eje V de DSM IV-TR) y CIE-10.

La posibilidad de trabajar de un paciente con trastorno mental grave depende de distintos tipo de variables como:

1. El subtipo de enfermedad: evolución, estadio, gravedad y subtipo.

1.1. De la conciencia de enfermedad y del grado de adherencia al tratamiento.

1.2. Funciones ejecutivas: como la memoria y el aprendizaje verbal, la memoria de trabajo, la velocidad en el procesamiento de la información y la desorganización del pensamiento. Desde el reconocimiento de la importancia de los déficit neuropsicológicos en la esquizofrenia, los síntomas 
alucinatorios y delirantes se consideran secundarios al trastorno básico del procesado de información y de integración cognitivo funcional.

1.3. Intensidad y persistencia de los síntomas negativos deficitarios y de los positivos más allá de la fase aguda, y lograda la estabilización clínica, los pacientes presentan una considerable discapacidad funcional derivada de la progresión de los síntomas negativos, los déficit cognitivos y el aislamiento social.

Los síntomas negativos de la esquizofrenia pueden ser primarios y característicos de la misma, o bien secundarios a otros factores, como efecto secundario de la medicación neuroléptica. Los síntomas negativos primarios, ya presentes en la fase prodrómica, van aumentando en intensidad según aumenta la duración de la enfermedad, una progresiva alteración de las funciones cognitivas globales. Estos provocan en gran medida la incapacidad socio-laboral de los enfermos con esquizofrenia: dificultades de atención-concentración, déficit de memoria, limitaciones en la planificación, el autocuidado y la toma de relaciones, etc., déficit que se explican por alteración de los circuitos fronto-parieto-temporales.

2. Variables del enfermo: nivel educacional y cultural.

3. Variables socioeconómicas: discriminación, normativa facilitadora, situación económica.

4. Características del trabajo: así si se trata de una actividad en relación directa con personas, es necesario garantizar:

4.1. La adecuada competencia psicosocial: motivación, empatía y habilidades sociales, al mismo nivel de excelencia que en el ámbito instrumental.

4.2. Los adecuados recursos cognitivos como juicio de realidad, buen funcionamiento ejecutivo, memoria de trabajo, y capacidad de toma de decisiones complejas.

4.3. La ausencia de conductas de riesgo y de trastorno mental grave que provoque malestar clínicamente significativo o deterioro del funcionamiento socio laboral.

En el ámbito de los Servicios Sanitarios, la propia institución sanitaria a través del Servicio de Prevención de Riesgos Laborales, los sindicatos representativos del sector y los colegios profesionales, así como todos los trabajadores individualmente tienen la responsabilidad compartida de mantener la calidad asistencial óptima, la seguridad de los pacientes, así como la satisfacción de todas las personas implicadas en la actividad laboral.

En cuanto a la evaluación psicosocial de un paciente con trastorno mental grave es importante precisar su capacidad laboral, al igual que su capacidad parental para el cuidado de los hijos, si los hubiese; con el compromiso de apoyar sus recursos sanos disponibles y el de prevenir la frecuente discriminación asociada a la enfermedad, así como de otros riesgos para él mismo y/o para otras personas.

La esquizofrenia implica una desorganización mental profunda que puede impedir cualquier actividad laboral (Carpio González, 2007; Stenberg, Holder y Tallur, 1998; Arechedera Aranzadi, 2004). Salvo en empleos de baja complejidad (escasas demandas en relación con los recursos disponibles), suelen ser pacientes que no conservan un puesto de trabajo competitivo.

Así, en el caso de episodios psicóticos breves con buenas respuesta al tratamiento, en pacientes con indicadores de buen pronóstico (ver tabla 3 ), en situación de recuperación clínica completa y buena adherencia al tratamiento prescrito, pueden reincorporarse a su trabajo previo, cuando se pueda garantizar una supervisión eficaz y la prevención de riesgos conductuales para sí mismo o para otros.

$\mathrm{Al}$ contrario, la esquizofrenia con predominio de síntomas negativos y déficit neurocognitivo intenso, con dificultades graves para mantener un juicio lúcido de realidad, están en general incapacitados para cualquier tipo de actividad laboral, aunque estuvieren controlados los síntomas positivos, salvo en el caso de trabajos protegidos y con una supervisión de calidad, como indican Ferreras de la Fuente y colaboradores en el Manual de Valoración de la Incapacidad Laboral en las Enfermedades Psiquiátricas.

Estas personas son especialmente vulnerables al estrés y a presentar nuevas recaídas, por lo que es necesario establecer objetivos realistas en cuanto a funcionamiento laboral y social, con los apoyos psicosociales más convenientes en cada caso, como poder mantener un empleo subvencionado en talleres protegidos. La actividad laboral, como la participación en la familia, puede tener tanto efectos beneficiosos y protectores (ingresos económicos, realización de capacidades, sensación de pertenencia social, etc.), como perturbadores o estresantes. 
El modelo de empleo subvencionado se caracteriza por:

a) Servicios que se centren en el empleo competitivo.

b) Elegibilidad en función de las preferencias del usuario.

c) Búsqueda rápida de empleo.

d) Integración del tratamiento psiquiátrico y de la rehabilitación psicosocial y laboral.

e) Apoyo individualizado e indefinido.

Existen varios estudios que respaldan el empleo subvencionado, frente al tratamiento en centro de día. Por ello en la Guía Clínica para el tratamiento de la esquizofrenia (2005) se recomienda ofrecer empleo subvencionado a las personal con esquizofrenia que tengan interés en trabajar y no puedan encontrar un empleo común, acorde con sus competencias laborales.

Como aseguraba Freud (1930) "el trabajo tiene mayor efecto que ninguna otra técnica vital para vincular al individuo estrechamente a la realidad... al menos en su trabajo, se encuentra ligado con seguridad a una parte de la realidad... la comunidad humana". El trabajo proporciona beneficios objetivos (mejora de la autoestima, relaciones interpersonales, etc.) y requiere realizar un esfuerzo adaptativo que produce satisfacciones y cierto grado de estrés o desgaste de energía.
A pesar del estereotipo evolutivo negativo de la enfermedad que, al menos en parte, se desarrolló por las creencia pesimistas de Kraepelin acerca del lento deterioro progresivo de los pacientes con esquizofrenia, la mayoría de ellos "tres quintas partes de los pacientes esquizofrénicos presentan un buen pronóstico; esto significa que se recuperan o muestran una clara mejoría". (Ciompi, 1980).

\section{EPISODIO PSICÓTICO BREVE. CAPACI- TACIÓN LABORAL}

Por definición el T. P. Breve evoluciona en, aproximadamente, un mes, con restitución completa del funcionamiento psíquico previo. No es infrecuente que presenten más adelante otros trastornos psiquiátricos incluyendo los crónicos, pero en sí mismo el pronóstico es favorable.

La valoración de la capacitación laboral sería la de la patología de base y que suele corresponder a un Trastorno de Personalidad. Los Trastornos de Personalidad "per se" no suelen ser causa de invalidad, a excepción de algunos T. Límites graves de peor evolución y determinados T. Esquizoides.

Los T. de Personalidad inducen un alto porcentaje de conflictos laborales, especialmente en las relaciones interpersonales. Toleran mal las situaciones estresantes y su capacidad de adaptación al medio está disminuida. Los entornos estables y las adaptaciones laborales adecuadas facilitan la integración de los pacientes y un desarrollo profesional "suficiente". A pesar de los frecuentemente inevitables períodos de Incapacidad Transitoria. 


\section{BIBLIOGRAFÍA}

- ALFARO, R.: Aplicación del Proceso de Enfermería. Doyma, Barcelona, 1988.

- ARRECHEDERRA ARANZADI, J.J.: Psiquiatría y ley. El enfermo mental ante la ley. Madrid, 2004.

- ASNIS G.M.; KAPLAN M.L.; HUNDORFEAN, G. $\mathrm{y}$ otros: Violence and homicidal be hariours in psychiatric disorders. Psychiatric Clinical of North America, 1997, 45: 133-137.

- ASOCIACIÓN MÉDICA AMERICANA: "Guías para la evaluación de las deficiencias permanentes". Madrid, INSERSO, 1994.

- BOBES GARCÍA, J. (Coordinador): Salud Mental. Enfermería psiquiátrica. Síntesis, 1994.

- BRODSKY, C.M.; EPSTEIN,L.J.: The psychiatric disorders of aging in the work organization. Ocupational Medicine, 1996, 11 (4): 739-744.

- CALCEDO ORDOÑEZ A.: Psiquiatría y ley. En: Tratado de Psiquiatría. Dirigido por Julio Vallejo Ruiloba y Carmen Leal Cerós. Cap. 152, pp. 2357-2373. Ars Médica, Barcelona, 2005.

- CARPIO GONZÁLES, M.: Manual de la incapacidad permanente. Almuzara, Madrid, 2007.

- CIOMPI, L.: The natural history or schizophrenia in the comp. term. British Journal of Psichiatry 136, 413420, 1980.

- CRESPO HERVÁS, M.D.: Rehabilitación y psicoeducación en la esquizofrenia. Cap. 33. En: Las esquizofrenias. Sus hechos y valores clínicos y terapéuticos. Elserier, Masson, Madrid, 2007.

- CHINCHILLA MORENO A.: Desde lo conceptual esquizofrénico hasta su comprensión y clínica. Cap. 16. Las esquizofrenias. Sus hechos y valores clínicos y terapéuticos. Elserier, Masson, Madrid, 2007.

- DABAN C, MARTÍNEZ ARÁN A, COLÓN F, REINARES M, BENABARRE A, VIETA E.: Disfunciones cognitivas en el trastorno bipolar y en la inteligencia. En trastornos cognitivos en las Psicos. Aula

- FARID, I. BRODSKY, C.M.: The Management of psychopathology in the workplace. Occupational Medicina, 1996, 11 (4): 617-650.
- FULLER TORREY, E.: Superar la esquizofrenia. Planeta, Barcelona, 2006.

- GONZÁLEZ CASES, J.C.; RODRÍGUEZ GONZÁLEZ, A.: Rehabilitación psicosocial y apoyo comunitario de personas con enfermedad mental crónica: programas básicos de intervención. Cuadernos Técnicos de Servicios Sociales. Comunidad de Madrid. Consejería de Servicios Sociales, Madrid, 2002.

- Guía Clínica para el tratamiento de la esquizofrenia, del Grupo de trabajo para la esquizofrenia, aprobada por la Asociación Psiquiátrica Americana. $2^{\mathrm{a}}$ edición. Ars Médic. Barcelona, 2005.

- LIPKIN, G.B. Y COHEN, R.G.: Cuidados de Enfermería en pacientes con conductas especiales. Doyma, Barcelona, 1989.

- MAC KINNON, R., MICHELS, R.: Psiquiatría clínica aplicada. Interamericana. México, 1973.

- MEKENNA, P.J.: Schizophrenia and related eyndromes. Routledge, Londres, 2007.

- Organización Mundial de la Salud. Clasificación Internacional del Funcionamiento, de la Discapacidad y de la Salud (CIF). Ministerio de Trabajo y Asuntos Sociales. Madrid, 2001.

- REBOLLEDO MOLLER, S.; LOBATO RODRÍGUEZ, $M^{\mathrm{a}}$ J.: Psicoeducación de personas vulnerables a la esquizofrenia. Fundació Nou Camí. Barcelona, 1998.

- STENBERG,C.; HOLDER, J.; TELLUR, K.:Psicosis relacionadas con el trabajo. Enciclopedia de salud y seguridad en el trabajo. Ministerio de Sanidad y Consumo, Madrid, 1998.

- SWANSON, D.W.; BOHNERT, P.J.; SMITH, J.A.: The paranoid. Little Brown, Boston, 1970.

- URIARTE, J.: Violencia, enfermedad mental y estigma. Disponible en Internet: www. psiquiatrialegal.org

- VALLEJO, J.: Árboles de decisión en Psiquiatría. $3^{\text {a }}$ edición. Barcelona: J\&C Ediciones Médicas, 2006.

- WEINBERGER, D.; BERMANK; ZEC, R.: Physiologic dysfunction o dorsolateral prefrontal cortex in schizophrenia. Archives General Psychiatry 43: 114-125, 1986.

- FREUD, S.: El malestar en la cultura. 
